\title{
Factors associated with symptomatic pseudotumors following metal-on-metal total hip arthroplasty
}

\author{
Masahiro Hasegawa*, Yohei Naito, Toshio Yamaguchi, Shinichi Miyazaki, Hiroki Wakabayashi and Akihiro Sudo
}

\begin{abstract}
Background: Pseudotumors associated with metal-on-metal hips can be symptomatic or asymptomatic. The purpose of this study was to identify the characteristics of pseudotumors associated with pain.

Methods: A total of 239 large-diameter, metal-on-metal total hip arthroplasties (THAs) were performed in 222 patients. Screening for pseudotumors was performed using magnetic resonance imaging (MRI) in all patients who underwent metal-on-metal THA, and 57 patients with 62 affected hips showed pseudotumors. There were 45 women with 49 hips and 12 men with 13 hips affected, with a mean age of 64 years and a mean body mass index (BMI) of $23.9 \mathrm{~kg} / \mathrm{m}^{2}$. Sixteen hips had symptomatic pseudotumors with pain, and 46 hips were asymptomatic. Pseudotumor size was determined. The anatomical position of pseudotumors was divided into anterior position and posterolateral position. Types of pseudotumors were divided into two types: cystic type; and mixed solid cystic and solid type without a cystic component. The follow-up study of pseudotumors was determined using MRI in 33 patients. The serum cobalt and chromium ion levels were measured in 38 patients after unilateral THA. Univariate and multivariate analyses were performed comparing symptomatic and asymptomatic patients to identify the characteristics of symptomatic pseudotumors.
\end{abstract}

Results: The mean BMI was $25.4 \mathrm{~kg} / \mathrm{m}^{2}$ in symptomatic patients and $23.4 \mathrm{~kg} / \mathrm{m}^{2}$ in asymptomatic patients; a higher $\mathrm{BMI}$ was associated with symptoms $(P=0.036)$. Symptomatic pseudotumors were significantly larger (three-fold) than asymptomatic pseudotumors $\left(1812 \mathrm{~mm}^{2}\right.$ vs $\left.642 \mathrm{~mm}^{2}, P=0.003\right)$. Pseudotumors located in the anterior position were associated with symptoms $(P=0.032)$, and mixed solid cystic and solid type pseudotumors were associated with symptoms $(P=0.007)$. A multivariate analysis showed significant differences only in size $\left(R^{2}=0.298\right.$, $P=0.031$ ). No asymptomatic patients with pseudotumors became symptomatic during the follow-up period of MRI evaluation.

Conclusion: Larger size was a significant factor for pain on multivariate analysis.

Keywords: Total hip arthroplasty, Metal-on-metal, Pseudotumor, Magnetic resonance imaging

\section{Background}

Pseudotumors associated with metal-on-metal hips are common in resurfacing and total hip arthroplasty (THA). Pseudotumors, including asymptomatic cases, have been reported in up to $69 \%$ of cases when patients are screened after metal-on-metal hip resurfacing or THA [1-9]. Pseudotumors can be asymptomatic or have a wide variation in presentations, not only with pain and discomfort

\footnotetext{
* Correspondence: masahase@clin.medic.mie-u.ac.jp Department of Orthopaedic Surgery, Mie University Graduate School of

Medicine, 2-174 Edobashi, Tsu City, Mie 514-8507, Japan
}

in the groin, but also with cup loosening or nerve palsy $[2,4,5,7,8]$. In addition, the prevalence of pseudotumors was reported to be similar in wellfunctioning patients and patients with painful metal-onmetal hip implants [10]. Magnetic resonance imaging (MRI) provides sensitive screening of pseudotumors following metal-on-metal hip implants. MRI is ideally suited for assessment of these patients and complements standard clinical evaluation $[11,12]$.

It remains unclear whether asymptomatic patients with pseudotumors become symptomatic and whether 
the presence of symptoms correlates with MRI findings and patients' characteristics. The purpose of this study was to identify the factors associated with symptomatic and asymptomatic pseudotumors. We hypothesized that the pseudotumors would be larger in symptomatic patients and asymptomatic pseudotumors has specific factors not to become symptomatic.

\section{Methods}

A total of 239 large-diameter, metal-on-metal THAs were performed in 222 patients. THA devices included 108 Cormet (Corin, Cirencester, UK), 80 Ultamet (DePuy, Warsaw, IN), and 51 Conserve Plus (Wright Medical Technology, Arlington, TN). Screening for pseudotumors was performed using MRI after THA. Pseudotumors were defined as any mass around the hip joint. MRI studies were conducted in all subjects regardless of symptoms to ensure that asymptomatic pseudotumors could be detected. The mean time at last follow-up with MRI was 49 months (22-85 months). A 1.5-T scanner was used with T1-weighted spin-echo (SE), T2weighted SE, and short tau inversion recovery (STIR) sequences (Signa; General Electric Healthcare, Waukesha, WI, USA) (Table 1). An eight-channel cardiac coil (GE Healthcare) was used. Two-dimensional fast spin echo images were obtained using modifications to the pulse parameters to reduce susceptibility artifact. A wider receiver bandwidth and oversampling in the frequency encoding axis were used to increase the strength of the readout gradient [13].

Fifty-seven patients with 62 affected hips showed pseudotumors (28 Cormet, 19 Ultamet, and 15 Conserve Plus). There were 45 women with 49 hips and 12 men with 13 hips, with a mean age of 64 years and a mean body mass index (BMI) of $23.9 \mathrm{~kg} / \mathrm{m}^{2}$. The primary diagnoses were osteoarthritis in 54 patients and rheumatoid arthritis in three patients. Sixteen hips had symptomatic pseudotumors with pain, and 46 hips were asymptomatic. Fourteen of 16 symptomatic hips had undergone revision surgery. Symptoms disappeared after revision in all revised patients. The Cormet cup was made of cobalt-chromium alloy with a titanium porous coating for bone ingrowth. The Pinnacle cup, which was made of titanium alloy, was a modular cup with a titanium porous coating; a cobalt-chromium alloy liner was inserted in the cup. The Conserve Plus cup was made of a cobalt-chromium alloy with a cobalt-chromium alloy bead coating. The head was made of cobalt-chromium alloy in all implants. The mean head diameter of Cormet devices was $43 \mathrm{~mm}$ (40-48 $\mathrm{mm}$ ). The head diameter for Pinnacle devices was $36 \mathrm{~mm}$ in all hips. The mean head diameter of Conserve Plus devices was $47 \mathrm{~mm}$ (44$52 \mathrm{~mm}$ ). The acetabular component inclination angle was measured on anteroposterior pelvic radiographs. The inclination angle was defined as the angle between the line joining the inferior teardrop points and the axis of the opening of the acetabular component. Acetabular anteversion was measured with computer software (Advanced CasePlan Digital Templating Planning Software, Stryker Orthopedics, Mahwah, NJ) [14]. The mean inclination angle of the cup was $44^{\circ}\left(23-70^{\circ}\right)$, and the mean anteversion angle was $14^{\circ}\left(4-25^{\circ}\right)$.

Pseudotumor size was determined on MRI by one investigator $(\mathrm{MH})$, manually outlining the greatest axial size of the mass. This investigator had 4 years of experience in MRI evaluation of postoperative hips. The area of the pseudotumor was measured using computer software (EV Insite Version 2.10.7.108; PSP Corporation, Tokyo, Japan) (Fig. 1). The scan areas were obtained from the same image for each longitudinal comparison. The anatomical position of pseudotumors was divided into anterior position and posterolateral position. When both positions were involved, the hip was classified based on the larger size. Pseudotumors were located in the anterior position in 23 hips and in the posterolateral position in 39 hips. Types of pseudotumors were divided into two types [4, 15]: cystic type (35 hips) and mixed solid cystic type and solid type without a cystic component (27 hips) (Fig. 2). The follow-up study of pseudotumors was determined using MRI in 33 patients. The mean time between the first MRI and the follow-up MRI was 24 months (8-66 months). Whether asymptomatic

Table 1 Pulse sequence protocol for MR imaging

\begin{tabular}{|c|c|c|c|c|c|}
\hline & Coronal T1 SE & Coronal T2 SE & Coronal STIR & Axial T1 SE & Axial STIR \\
\hline Repetition time (msec) & $450-560$ & $3000-4090$ & $5000-7600$ & $450-500$ & $5000-7600$ \\
\hline Echo time (msec) & $9-14$ & $94-100$ & $69-77$ & $13-14$ & $69-77$ \\
\hline Inversion time (msec) & & & 150 & & 150 \\
\hline Receiver band-width ( $\mathrm{Hz}$ per pixel) & $300-400$ & $300-400$ & $300-400$ & $300-400$ & $300-400$ \\
\hline Flip angle (degrees) & 90 & 90 & 90 & 90 & 90 \\
\hline Field of view (mm) & $340 \times 340$ & $340 \times 340$ & $340 \times 340$ & $340 \times 340$ & $340 \times 340$ \\
\hline Matrix & $512 \times 512$ & $512 \times 512$ & $512 \times 512$ & $512 \times 512$ & $512 \times 512$ \\
\hline Section thickness (mm) & $4-6$ & $4-6$ & $4-6$ & $4-6$ & $4-6$ \\
\hline
\end{tabular}




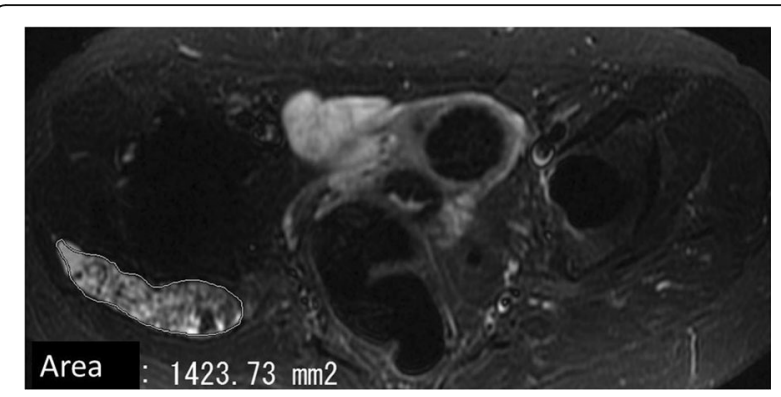

Fig. 1 Measurement of pseudotumor size on a magnetic resonance image by manually outlining the greatest size of the mass using computer software

patients with pseudotumors became symptomatic was examined, and the growth rate of pseudotumors was determined from follow-up MRIs. The serum cobalt and chromium ion levels were measured closest to the date of the MRI in 38 patients after unilateral THA (11 symptomatic and 27 asymptomatic patients). Cobalt levels were assayed using Inductively Coupled Plasma Mass Spectrometry (Perkin-Elmer SCIEX Elan 6100 DRC ICPMS system; Perkin-Elmer Instruments, Norwalk, CT) at Mayo Medical Laboratories (Rochester, MN), and chromium levels were assayed using a graphite furnace atomic absorption spectrometer (Z-5700; Hitachi Ltd., Tokyo, Japan) with polarization-Zeeman absorption at Mitsubishi Chemistry Medience Co., Ltd. (Tokyo, Japan). Detection limits for each ion were $0.2 \mu \mathrm{g} / \mathrm{L}$ [16]. This study was approved by the local institutional review board, and all patients provided their informed consent.

\section{Statistical analysis}

The Mann-Whitney $U$ test was used to compare age, BMI, femoral head diameter, acetabular cup inclination and anteversion angles, time of MRI screening, pseudotumor size, and serum cobalt and chromium ion levels between symptomatic and asymptomatic patients. The chi-squared test and Fisher's exact test were used to compare sex, position of pseudotumors, pseudotumor type, and changes of pseudotumor size between the groups. Multiple regression analysis was also performed. Statistical significance was set at $P<0.05$. Statistical analysis was performed using SPSS version 22 (SPSS, Inc, Chicago, IL).

\section{Results}

The mean BMI was $25.4 \mathrm{~kg} / \mathrm{m}^{2}$ in symptomatic patients and $23.4 \mathrm{~kg} / \mathrm{m}^{2}$ in asymptomatic patients; higher BMI was associated with symptoms $(P=0.036$, Table 2$)$. Symptomatic pseudotumors were significantly larger (three-fold) than asymptomatic pseudotumors $(P=0.003$, Table 2). Pseudotumors located in the anterior position were associated with symptoms $(P=0.032$, Table 2$)$, as were mixed solid cystic and solid type pseudotumors $(P=0.007$, Table 2). Other factors were not significantly different between the groups (Table 2). The growth rate of asymptomatic pseudotumors was 132 $\pm 502 \mathrm{~mm}^{2} /$ year. On multivariate analysis, a significant difference was seen only in size $\left(R^{2}=0.298, P=\right.$ 0.031). BMI $(P=0.100)$, position $(P=0.116)$, and type $(P=0.161)$ showed no significant differences on multivariate analysis. No asymptomatic patients with pseudotumors became symptomatic during the MRI follow-up period.

\section{Discussion}

Pseudotumors following metal-on-metal hip arthroplasty are an important problem. Early and accurate diagnosis of a pseudotumor is crucial to plan further management of this potentially devastating complication because late revision surgeries can have poor outcomes [17, 18]. However, previous longitudinal studies demonstrated disappearance of pseudotumors [19-21]. We confirmed that pseudotumors frequently change in size [22] on longitudinal assessment with MRI after metal-on-metal THA. Some patients with pseudotumors following metal-on-metal arthroplasty have severe soft tissue damage resulting in early failure. In contrast, some patients
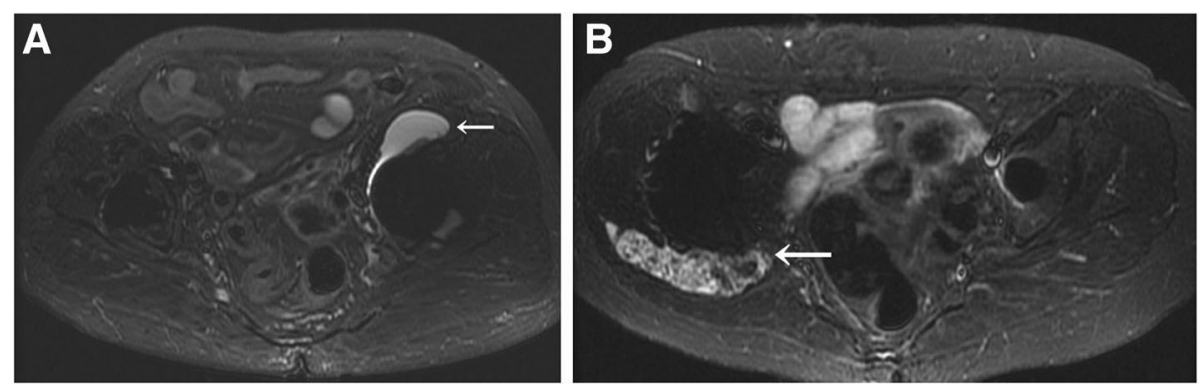

Fig. 2 Magnetic resonance images (transverse short tau inversion recovery images) showing pseudotumors (arrows) of the cystic type (a) and the mixed solid cystic type (b) 
Table 2 Risk factors associated with symptomatic pseudotumors

\begin{tabular}{|c|c|c|c|}
\hline & Symptomatic & Asymptomatic & $P$ \\
\hline \multicolumn{4}{|l|}{ Sex } \\
\hline Female & 15 & 34 & 0.154 \\
\hline Male & 1 & 12 & \\
\hline Age $(\text { years })^{a}$ & 63.1 & 64.1 & 0.803 \\
\hline BMI $\left(\mathrm{kg} / \mathrm{m}^{2}\right)^{\mathrm{a}}$ & 25.4 & 23.4 & 0.036 \\
\hline Head diameter $(\mathrm{mm})^{\mathrm{a}}$ & 42.6 & 41.7 & 0.454 \\
\hline Cup inclination $\left({ }^{\circ}\right)^{a}$ & 45.2 & 43.5 & 0.790 \\
\hline Cup anteversion $\left({ }^{\circ}\right)^{\mathrm{a}}$ & 14.1 & 13.3 & 0.494 \\
\hline Time of MRI screening (months) ${ }^{a}$ & 45.7 & 49.7 & 0.359 \\
\hline Pseudotumor size $\left(\mathrm{mm}^{2}\right)^{a}$ & 1812 & 642 & 0.003 \\
\hline \multicolumn{4}{|l|}{ Position of pseudotumor } \\
\hline Anterior & 10 & 13 & 0.019 \\
\hline Posterolateral & 6 & 33 & \\
\hline \multicolumn{4}{|l|}{ Pseudotumor type } \\
\hline Cystic & 4 & 31 & 0.007 \\
\hline Mixed cystic solid and solid & 12 & 15 & \\
\hline \multicolumn{4}{|l|}{ Change of pseudotumor size } \\
\hline Decreased & 2 & 6 & 0.083 \\
\hline Increased & 4 & 8 & \\
\hline No change & 0 & 13 & \\
\hline Cobalt level $(\mu \mathrm{g} / \mathrm{L})^{\mathrm{a}}$ & 11.7 & 8.8 & 0.176 \\
\hline Chromium level $(\mu \mathrm{g} / L)^{a}$ & 10.3 & 6.2 & 0.171 \\
\hline
\end{tabular}

with pseudotumors have no symptoms. Asymptomatic pseudotumors have been reported to occur in 27 to $73 \%$ of cases (Table 3) $[2,7,8,10]$. It is desirable to determine the characteristics of symptomatic pseudotumors.

Chang et al. [3, 23] reported that pseudotumor size was not associated with symptoms. However, other studies $[2,7]$ demonstrated larger pseudotumors in symptomatic patients, similar to the present study's finding. Hart et al. [10] confirmed that the presence of a fluidfilled lesion (cystic type) visible on MRI had less clinical importance, but they were concerned about solid pseudotumors. Hauptfleisch et al. [24] reported that predominantly solid (mixed type) pseudotumors were associated with a higher likelihood of symptoms than cystic pseudotumors. The present results support these findings. In terms of metal ion concentrations, a recent study by Sutphen et al. [8] demonstrated that elevated serum cobalt levels might be associated with symptoms. However, the present study, as well as the study by Chang et al. [23], showed no significant correlation with symptoms.

Guidelines recommending follow-up of asymptomatic patients undergoing metal-on-metal hip arthroplasty have already been published [25]; however, the indications for operative revision have yet to be established. In our institution, revision is recommended for patients with painful hips with pseudotumors.

Pseudotumors observed in asymptomatic patients could eventually become symptomatic [23]. One of the strengths of this study was that the follow-up study of asymptomatic patients with pseudotumors was observed, and no asymptomatic patients with pseudotumors became symptomatic during the MRI follow-up period.

This study has some limitations. First, a small number of patients was studied. Second, the follow-up period was short. A longer follow-up study will be necessary. Third, there is no standardized definition of pseudotumor in the literature. It is likely that, in some patients with cystic pseudotumor, its presence is not a result of an abnormal tissue reaction, but rather fluid accumulation [22].

\section{Conclusions}

Higher BMI, larger pseudotumor size, pseudotumors in the anterior position, and mixed solid cystic and solid type of pseudotumors were predictors of symptoms on univariate analyses. For these patients, longer follow-up studies are required. However, larger size was the only significant factor for symptoms on multivariate analysis, and our first hypothesis was verified. If asymptomatic patients with pseudotumors are asymptomatic at followup MRI, especially with pseudotumors small in size in the posterolateral position, and of cystic type, further MRI follow-up may not be indicated because these patients have less chance to become symptomatic. Asymptomatic pseudotumors with small in size in the posterolateral position, and of cystic type could be specific factors not to become symptomatic. And our second hypothesis was verified.

Table 3 Prevalence of symptoms with pseudotumors and associated factors

\begin{tabular}{|c|c|c|c|c|}
\hline Authors & $n$ & Symptomatic (\%) & Asymptomatic (\%) & Factor associated with symptoms \\
\hline Hart et al. [10] & 34 & $17(50)$ & $17(50)$ & \\
\hline Sutphen et al. [8] & 70 & $31(44)$ & $39(56)$ & Elevated serum cobalt level \\
\hline Bisschop et al. [2] & 40 & $11(28)$ & $29(73)$ & Larger pseudotumors \\
\hline Nawabi et al. [7] & 55 & $40(73)$ & $15(27)$ & Larger pseudotumors \\
\hline Current study & 62 & $16(26)$ & $46(74)$ & Larger pseudotumors \\
\hline
\end{tabular}




\section{Abbreviations}

BMl: Body mass index; MRI: Magnetic resonance imaging; STIR: Short tau inversion recovery; THA: Total hip arthroplasty

\section{Acknowledgements}

Not applicable.

\section{Funding}

This study was not supported by any funding.

\section{Availability of data and materials}

We had full access to all of the data in the study and take responsibility for the integrity of the data and the accuracy of the data analysis. The data is available on request from the corresponding author.

\section{Authors' contributions}

$\mathrm{MH}$ participated in the design of the study and drafted the manuscript. $Y H, T Y$, and $W H$ helped to draft the manuscript. SM reviewed the statistical analysis. AS participated in its design and coordination. All authors read and approved the final manuscript.

\section{Competing interests}

The authors declare that they have no competing interests.

\section{Consent for publication}

Consent for publication in the study was obtained.

\section{Ethics approval and consent to participate}

This study was approved by the ethics committee of Mie University. All patients provided their informed consent.

Received: 6 July 2016 Accepted: 1 November 2016

Published online: 07 November 2016

\section{References}

1. Bayley N, Khan H, Grosso P, Hupel T, Stevens D, Snider M, Schemitsch E, Kuzyk P. What are the predictors and prevalence of pseudotumor and elevated metal ions after large-diameter metal-on-metal THA? Clin Orthop Relat Res. 2015:473:477-84.

2. Bisschop R, Boomsma MF, Van Raay JJ, Tiebosch AT, Maas M, Gerritsma CL. High prevalence of pseudotumors in patients with a Birmingham Hip Resurfacing prosthesis: a prospective cohort study of one hundred and twenty-nine patients. J Bone Joint Surg Am. 2013;95:1554-60.

3. Chang EY, McAnally JL, Van Horne JR, Statum S, Wolfson T, Gamst A, Chung CB. Metal-on-metal total hip arthroplasty: do symptoms correlate with MR imaging findings? Radiology. 2012;265:848-57.

4. Hasegawa M, Yoshida K, Wakabayashi H, Sudo A. Prevalence of adverse reactions to metal debris following metal-on-metal THA. Orthopedics. 2013;36:e606-12

5. Kwon YM, Ostlere SJ, McLardy-Smith P, Athanasou NA, Gill HS, Murray DW. "Asymptomatic" pseudotumors after metal-on-metal hip resurfacing arthroplasty: prevalence and metal ion study. J Arthroplasty. 2011;26:511-8

6. Macnair RD, Wynn-Jones H, Wimhurst JA, Toms A, Cahir J. Metal ion levels not sufficient as a screening measure for adverse reactions in metal-onmetal hip arthroplasties. J Arthroplasty. 2013:28:78-83.

7. Nawabi DH, Hayter CL, Su EP, Koff MF, Perino G, Gold SL, Koch KM, Potter HG. Magnetic resonance imaging findings in symptomatic versus asymptomatic subjects following metal-on-metal hip resurfacing arthroplasty. J Bone Joint Surg Am. 2013:95:895-902.

8. Sutphen SA, MacLaughlin LH, Madsen AA, Russell JH, McShane MA. Prevalence of Pseudotumor in Patients After Metal-On-Metal Hip Arthroplasty Evaluated with Metal Ion Analysis and MARS-MRI. Radiology. 2012;265:848-57.

9. Williams DH, Greidanus NV, Masri BA, Duncan CP, Garbuz DS. Prevalence of pseudotumor in asymptomatic patients after metal-on-metal hip arthroplasty. J Bone Joint Surg Am. 2011;93:2164-71.

10. Hart AJ, Satchithananda K, Liddle AD, Sabah SA, McRobbie D, Henckel J, Cobb JP, Skinner JA, Mitchell AW. Pseudotumors in association with well-functioning metal-on-metal hip prostheses: a case-control study using three-dimensional computed tomography and magnetic resonance imaging. J Bone Joint Surg Am. 2012;94:317-25.
11. Campe CB, Palmer WE. MR imaging of metal-on-metal hip prostheses Magn Reson Imaging Clin N Am. 2013;21:155-68.

12. Hayter $\mathrm{CL}$, Koff MF, Potter HG. Magnetic resonance imaging of the postoperative hip. J Magn Reson Imaging. 2012;35:1013-25.

13. Suh JS, Jeong EK, Shin KH, Cho JH, Na JB, Kim DH, Han CD. Minimizing artifacts caused by metallic implants at MR imaging: experimental and clinical studies. AJR Am J Roentgenol. 1998;171:1207-13.

14. Levine B, Fabi D, Deirmengian C. Digital templating in primary total hip and knee arthroplasty. Orthopedics. 2010;33:797.

15. Nawabi DH, Gold S, Lyman S, Fields K, Padgett DE, Potter HG. MRI predicts ALVAL and tissue damage in metal-on-metal hip arthroplasty. Clin Orthop Relat Res. 2014;472:471-81

16. Hasegawa M, Yoshida K, Wakabayashi H, Sudo A. Cobalt and chromium ion release after large-diameter metal-on-metal total hip arthroplasty. J Arthroplasty. 2012;27:990-6.

17. Grammatopoulos G, Pandit H, Kwon YM, Gundle R, McLardy-Smith P, Beard DJ, Murray DW, Gill HS. Hip resurfacings revised for inflammatory pseudotumour have a poor outcome. J Bone Joint Surg (Br). 2009;91:1019-24.

18. Matharu GS, Pynsent PB, Dunlop DJ. Revision of metal-on-metal hip replacements and resurfacings for adverse reaction to metal debris: a systematic review of outcomes. Hip Int. 2014:24:311-20.

19. Almousa SA, Greidanus NV, Masri BA, Duncan CP, Garbuz DS. The natural history of inflammatory pseudotumors in asymptomatic patients after metal-on-metal hip arthroplasty. Clin Orthop Relat Res. 2013;471:3814-21.

20. Ebreo D, Bell PJ, Arshad H, Donell ST, Toms A, Nolan JF. Serial magnetic resonance imaging of metal-on-metal total hip replacements. Follow-up of a cohort of 28 mm Ultima TPS THRs. Bone Joint J. 2013;95-B:1035-9.

21. Reito A, Elo P, Puolakka T, Pajamäki J, Nieminen J, Eskelinen A. Repeated magnetic resonance imaging in 154 hips with large-diameter metal-onmetal hip replacement. Acta Orthop. 2014;85:570-6.

22. Hasegawa M, Miyamoto N, Miyazaki S, Wakabayashi H, Sudo A. Longitudinal magnetic resonance imaging of pseudotumors following metal-on-metal total hip arthroplasty. J Arthroplasty. 2014;29:2236-8.

23. Chang EY, McAnally JL, Van Horne JR, Van Horne JG, Wolfson T, Gamst A, Chung CB. Relationship of plasma metal ions and clinical and imaging findings in patients with ASR XL metal-on-metal total hip replacements. J Bone Joint Surg Am. 2013;95:2015-20.

24. Hauptfleisch J, Pandit H, Grammatopoulos G, Gill HS, Murray DW, Ostlere S. A MRI classification of periprosthetic soft tissue masses (pseudotumours) associated with metal-on-metal resurfacing hip arthroplasty. Skeletal Radiol. 2012:41:149-55

25. Lombardi Jr AV, Barrack RL, Berend KR, Cuckler JM, Jacobs JJ, Mont MA, Schmalzried TP. The Hip Society: algorithmic approach to diagnosis and management of metal-on-metal arthroplasty. J Bone Joint Surg (Br). 2012:94(11 Suppl A):14-8.

\section{Submit your next manuscript to BioMed Central and we will help you at every step:}

- We accept pre-submission inquiries

- Our selector tool helps you to find the most relevant journal

- We provide round the clock customer support

- Convenient online submission

- Thorough peer review

- Inclusion in PubMed and all major indexing services

- Maximum visibility for your research

Submit your manuscript at www.biomedcentral.com/submit
) Biomed Central 